\title{
DOCUMENTACIÓN DE FOTOGRAFÍAS EN BANCOS DE IMÁGENES COMERCIALES
}

\section{Luisa Perdices-Castillo y Antonio Perianes-Rodríguez}

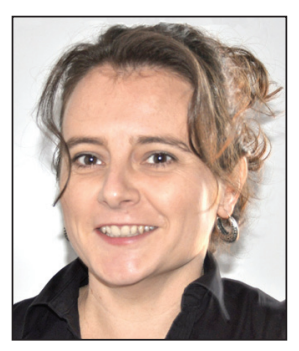

Luisa Perdices-Castillo es diplomada en biblioteconomía y documentación por la Universidad Carlos III de Madrid y licenciada en documentación por la Universidad de Alcalá de Henares. Ha trabajado en diversas empresas tecnológicas y publicaciones durante los últimos quince años. Es consultora y asesora de información digital de Limited Pictures y Alfaquí Fotografía.

http://www.limitedpictures.com

http://orcid.org/0000-0002-2103-9188

Limited Pictures

Antonio López, 48 -2C. 28019 Madrid, España marisaperdices@limitedpictures.com

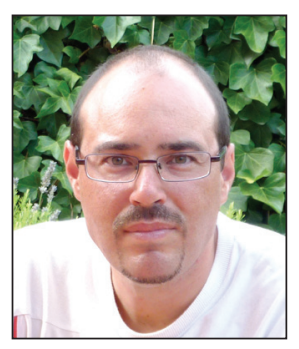

Antonio Perianes-Rodríguez es profesor ayudante doctor en el Departamento de Biblioteconomía y Documentación de la Universidad Carlos III de Madrid e investigador del grupo SCImago. http://portal.uc3m.es/portal/page/portal/grupos_investigacion/SCImago/Perianes http://orcid.org/0000-0002-1188-3481

Univ. Carlos III de Madrid, Dpto. Biblioteconomía y Documentación Madrid, 128. 28903 Getafe (Madrid), España antonio.perianes@uc3m.es

\section{Resumen}

Las imágenes digitales inundan nuestra vida y su número se incrementa diariamente. Sin embargo, ese volumen creciente contrasta con su escasa o nula descripción. El valor de esas instantáneas, bien para ilustrar el acontecimiento que las justifica, bien para ser empleadas en otros contextos o situaciones, pasa por su adecuada descripción. Mediante la tipificación de agencias e imágenes, la especificación de sus usos y la ejemplificación de las diferencias descriptivas que las caracterizan se pueden conseguir descripciones equilibradas que eviten registros escuetos o incompletos, excesivamente recargados o irreales. La aplicación de las recomendaciones propuestas mejorará la calidad de las descripciones, facilitará el éxito en la recuperación, ayudará en la difícil tarea de normalizar y aumentará las valoraciones positivas por parte de clientes y usuarios.

\section{Palabras clave}

Bancos de imágenes, Fotografía digital, Agencias de fotografía, Documentación fotográfica, Edición gráfica.

\section{Title: Image description by stock photography agencies}

\begin{abstract}
Digital images are all around and their number increases every day. However, this growing volume contrasts with poor image description in the vast majority of cases. The value of a picture to illustrate the original event, or to be used in other contexts or situations, is based on an appropriate description. The purpose of this paper is to reduce the difficulties encountered in describing images by suggesting ways of categorizing the images and the agencies, specifying uses, and illustrating descriptive differences. The implementation of these recommendations will improve the quality of records, help to achieve successful retrieval, and increase positive evaluations of web sites by clients and users.
\end{abstract}

\section{Keywords}

Stock photography, Digital photography, Photography agencies, Image description, Photo edition, Picture researcher.

Perdices-Castillo, Luisa; Perianes-Rodríguez, Antonio (2014). “Documentación de fotografías en bancos de imágenes comerciales". El profesional de la información, septiembre-octubre, v. 23, n. 5, pp. 534-542. 


\section{Introducción}

Estamos rodeados de imágenes a diario: portadas de libros, solapas, contraportadas, interiores, diccionarios y enciclopedias, libros de texto, manuales, guías turísticas, coleccionables, revistas y periódicos, medios sociales, da igual si en soporte papel o en formato digital, en programas de televisión, en móviles y tabletas, en webs. Los bancos de imágenes son las fuentes que nutren la mayor parte de estos productos, y son los lugares a los que recurren los editores gráficos, los especialistas en información y los periodistas para conseguir la ilustración perfecta del hecho, concepto, o idea que tienen en la cabeza o en el papel, tratando, además, de no repetir la fotografía que ya haya sido utilizada por cualquier otro medio.

Por ello, el valor de ilustración de una fotografía no está sólo en el acontecimiento o en el escenario que capta o representa en el momento de ser capturada. Más allá de ese objetivo inicial por el que fue tomada, puede servir para ilustrar muchas otras situaciones o contextos, dependiendo de las necesidades y los gustos del usuario final (libro de texto, revista, portada de libro). Una imagen hecha para cubrir un evento concreto o dejar constancia de una noticia actual puede ser reutilizada más tarde en un contexto o con una finalidad completamente diferente.

Su potencial está entonces en su adecuada, correcta y completa descripción, empleando para ello los metadatos que garanticen su adecuada recuperación. Es decir, su potencial futuro depende de la capacidad del especialista en información para analizarla detalladamente y ser capaz de detectar las necesidades futuras de los usuarios que podrán ser satisfechas con esa instantánea. Lo ideal, y precisamente esa es la filosofía y el negocio de los bancos de imágenes, es reutilizar las imágenes usándolas en distintas ocasiones y no sólo para ilustrar el acontecimiento para el que fueron tomadas, aumentando su rentabilidad y el beneficio derivado de esa inversión.

Al documentar una imagen hay que tener en cuenta el tipo de fotografía y el tipo de usuario final al que se dirige

\section{Justificación y objetivos}

Muchas editoriales, productoras o periódicos cuentan con su propio archivo gráfico y su equipo de fotógrafos. A pesar de ello, recurren frecuentemente a archivos externos y agencias de fotografías para satisfacer las cada vez más numerosas necesidades que sus propios medios no pueden cubrir.

Por otro lado, el enorme aumento del número de imágenes disponibles gracias a la fotografía digital, aunque no siempre en condiciones idóneas para su uso (la gran mayoría con escasa o nula descripción), hace imprescindible su organización para su fácil recuperación y utilización.

Numerosos trabajos se han centrado en la teoría relacionada con la descripción de fotografías. Unos abordándola des- de la perspectiva del documento fotográfico como material de archivo (Boadas; Casellas; Suquet, 2001; Charbonneau; Robert, 1999), otros desde la vertiente documental (Ménard; Smithglass, 2012; Robledano-Arillo, 2002; Rorissa, 2008; Del-Valle-Gastaminza, 2001; 1999), desde el matiz del modelo descriptivo más apropiado (Doucet, 2008; Iglesias-Franch, 2008; Lee; Neal, 2010; Robledano-Arillo; Moreiro-González, 2002), o desde la óptica de las búsquedas realizadas por usuarios (Hollink et al., 2004; Lin et al., 2008).

La variedad de trabajos y la diversidad de visiones de una misma cuestión anticipa la dificultad de normalizar la descripción de fotografías. Como señala Robledano-Arillo, el amplio abanico de situaciones y las necesidades de explotación tan variadas hacen que los modelos y criterios descriptivos también lo sean (Robledano-Arillo, 2007).

\section{La descripción depende del tema, ya que no se requieren las mismas especifica- ciones para una imagen deportiva que para una de moda o para una histórica}

Sin embargo, el desarrollo tecnológico actual hace que algunas de las discusiones de antaño se difuminen, especialmente para aquellos usuarios que esperan de los bancos de imágenes funcionamientos sencillos, fáciles y familiares, similares a los de los buscadores web tradicionales. Lo relevante, pues, no es si la descripción de la información debe ceñirse al contexto archivístico, primando el valor histórico o cultural, o debe circunscribirse al contexto comercial, primando el valor económico. Tampoco si el modelo descriptivo debe ajustarse al modelo IPTC, XMP, Dublin core o EXIF, por citar algunos de los más conocidos. Las condiciones actuales permiten que, con independencia del sistema descriptivo o de metadatos empleado, la información pueda ser fácilmente convertible a otros modelos, de forma similar a la interoperabilidad que presentan los gestores de referencias bibliográficas o los archivos abiertos, por ejemplo.

Por otro lado, la afirmación de Del-Valle-Gastaminza (1999) sobre las peculiaridades de la fotografía como tipo documental especial que precisa de un tratamiento descriptivo diferenciado, podría completarse añadiendo que, a su vez, los distintos tipos de fotografías requieren también un tratamiento descriptivo específico. Dicho de otro modo, que más allá de hablar de la descripción genérica de fotografías, sería necesario hablar de una descripción adaptada a cada tipo de fotografía en función de su tema, dado que no se requieren las mismas especificaciones para una imagen deportiva que para una de moda o para una histórica.

Por tanto, el objeto principal de este trabajo consiste en ayudar a reducir la dificultad inherente a la descripción de fotografías. Para ello se identificarán los tipos de agencias y de imágenes, los usos que éstas pueden tener, y se destacarán y ejemplificarán las diferencias descriptivas que las caracterizan con el fin de trascender los aspectos teóricos abordados en trabajos precedentes, todo ello basado en una visión práctica y actual de la cuestión que dé respuestas a la popularización del uso de este tipo de materiales. 


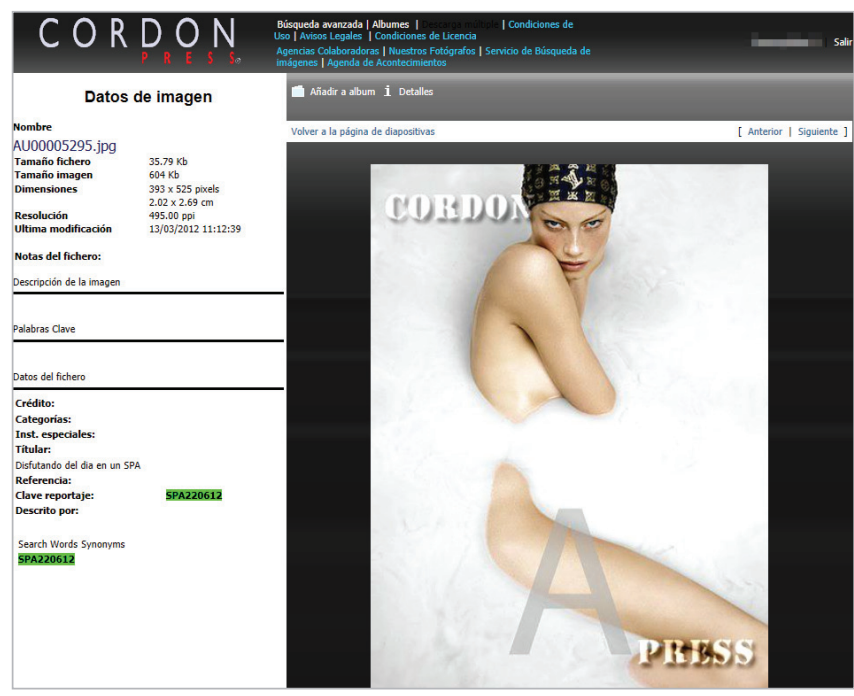

Figura 1. Ausencia de palabras clave y descripción en una fotografía de stock

\section{Descripción de imágenes}

La descripción de fotografías, como la de cualquier otro tipo documental, requiere la enumeración de sus cualidades y sus elementos esenciales con el fin de poner a disposición de los usuarios las imágenes que precisan. En definitiva, acompasar las necesidades de los usuarios y sus formas de búsqueda con los criterios descriptivos llevados a cabo por los bancos de imágenes para hacer visibles sus fondos (Muñoz-Castaño, 2001).

Una fotografía sin información tiene muchas más posibilidades de no ser utilizada que aquella adecuadamente descrita. Del mismo modo, imágenes descritas de manera inadecuada o con ausencia de información clave para su recuperación pasarán inadvertidas (figura 1), especialmente si el profesional no tiene en cuenta el significado cambiante que una instantánea puede adquirir con el paso del tiempo (Del-Valle-Gastaminza, 1999).

Existen también problemas con las prestaciones y usos de los sistemas de recuperación empleados por los bancos de imágenes. En este caso se solapan los problemas de la des-

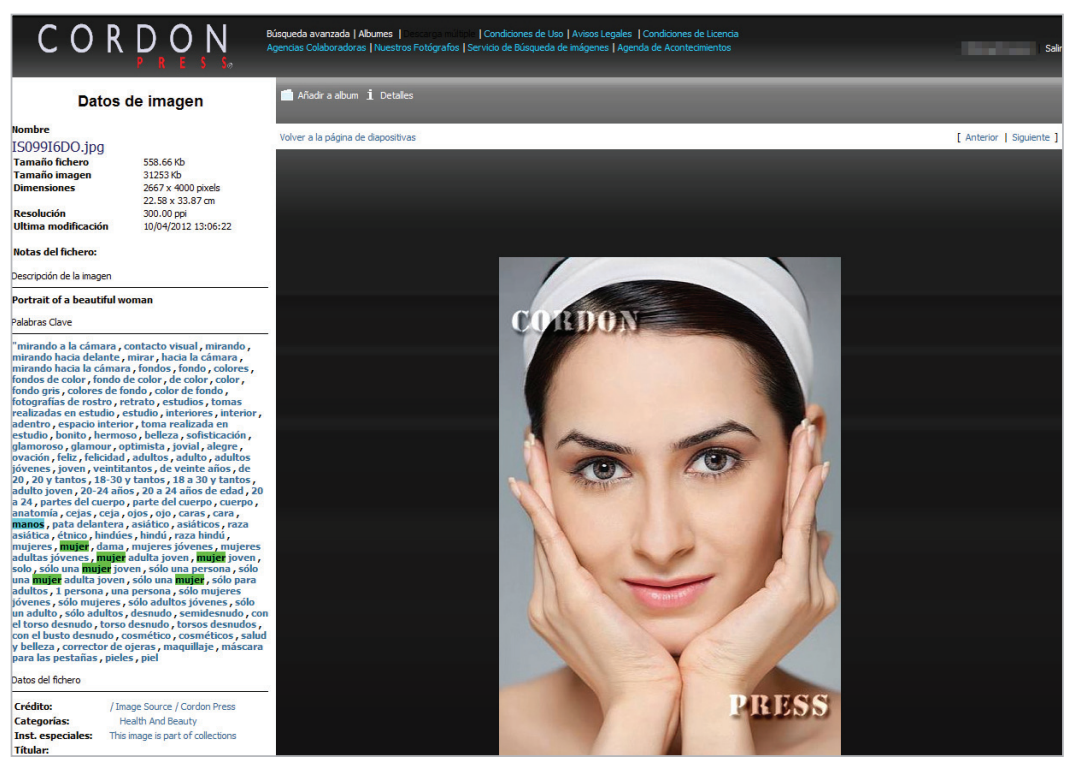

Figura 2. Exceso de palabras clave en la descripción de una fotografía de stock cripción con los propios del sistema, incluyendo la falta de homogeneidad en las formas de interacción o de recuperación de información. A este respecto, para eludir los inconvenientes de tipo tecnológico es preciso conocer las características básicas que todo buen banco de imágenes debe incluir (Perdices-Castillo; Perianes-Rodríguez, 2011).

A la hora de documentar una imagen hay que tener en cuenta al menos dos circunstancias: el tipo de fotografía ante la que nos encontramos y el tipo de usuario final al que se dirige, generalmente de los sectores creativo o editorial (Codina, 2011). En definitiva, debemos ser capaces de anticiparnos a las necesidades futuras que esa instantánea pueda cubrir, incluyendo sus posibilidades a la hora de ilustrar determinados temas o de apoyar en la representación de ciertos conceptos más o menos abstractos.

Hay una serie de datos que son imprescindibles para iniciar la documentación de una colección de imágenes, y que deben llegar al documentalista junto con las propias instantáneas. Parte de estos datos identificativos básicos son generados automáticamente por las cámaras digitales: fecha y hora de captura, obturación, apertura, distancia focal, lente, flash, índice ISO, tipo de medición, dimensiones, orientación, resolución, coordenadas GPS o espacio de color, entre otros.

También se incluirán otros elementos comunes a todos los tipos de imágenes, más físicos o morfológicos que de contenido, que resultan imprescindibles para la posterior acotación de las búsquedas y la consiguiente reducción del número de resultados:

- orientación de la imagen (horizontal, vertical, panorámica, cuadrada);

- estilo (color, blanco y negro, virados);

- gente (una persona, dos personas, grupo, multitud);

- resolución en puntos por pulgada (para web, pequeña, mediana, gran tamaño);

- tipo de imagen (fotografía, ilustración, vectorial);

- tamaño del fichero (en bytes).

Otros elementos de la descripción dependerán de la calidad de la información que el propio fotógrafo proporcione para la identificación de la fotografía o del reportaje. Para ello puede facilitar documentación complementaria como guías, hojas de ruta, apuntes o cuadernos de viaje, especialmente en el caso de reportajes de viajes o de acontecimientos con personajes concretos. A partir de esa información esencial, será labor exclusiva del especialista en información el análisis, la descripción y la adición de metadatos a cada fotografía para hacerla recuperable, potencialmente útil y vendible.

La descripción de imágenes requiere cuatro pasos fundamentales:

-identificar los aspectos físicos y morfológicos (color, dimensiones, orientación, tamaño, perfil, tipo de plano, tipo de vista, resolución, etc.), sin olvidar la acreditación (agencia y autor). 
- descripción del contenido, incluyendo todos los datos que ilustran el hecho en texto libre, y la incorporación de palabras clave adicionales que garanticen otros usos. Es preciso, sin embargo, encontrar el necesario equilibrio en las descripciones, sin excesos a la hora de incluir términos en la descripción o añadiendo excesivos detalles en el texto libre, situaciones que pueden ser contraproducentes en las consultas. La figura 2 incluye más de 100 palabras clave para describir la imagen, algunas de ellas incorrectas y otras muchas prescindibles;

- descripción abstracta incluyendo sentimientos, colores predominantes o sensaciones que inspira la imagen;

- especificar las condiciones especiales, precios, gestión de derechos o restricciones de uso (Getty Images, 2014).

A estas pautas generales de descripción se une el necesario conocimiento del uso que del sistema y de las búsquedas hacen los usuarios y clientes, incluyendo los contextos en los que emplean las imágenes. Este conocimiento se obtiene a partir del trabajo cotidiano en un archivo gráfico, a través del contacto directo con los clientes (editoriales de libros o revistas, periódicos, productoras), y mediante la observación de sus productos finales. Por tanto, es necesario que desde las agencias se analicen las búsquedas realizadas por sus clientes en sus webs, el tipo de imágenes que necesitan o que descargan y los términos de búsqueda que emplean para localizarlas. Esto permitirá un mejor conocimiento de sus necesidades y de las dificultades que encuentran, permitiendo la mejora del sistema informático, pero también del método de descripción (incorporar las palabras más utilizadas, ofrecer formación o ayudas eventuales para la realización de búsquedas, etc.).

Las agencias han de analizar las búsquedas realizadas por sus clientes y el tipo de imágenes que descargan

Aunque el fotógrafo debería editar su material antes de enviarlo y seleccionar las mejores imágenes y planos descartando el sobrante (imágenes repetitivas o defectuosas), es muy frecuente que el material llegue a la agencia sin editar. Será entonces el documentalista el encargado de realizar esa labor de selección y descarte, eliminando las series de fotos muy similares y conservando sólo los mejores planos, sin que esto suponga eliminar todas las fotos que no se ajusten a criterios artísticos o técnicos. Se trata de eliminar la repetición no las malas fotos o aquellas en las que el personaje no sale favorecido (figura 3). Estas últimas son frecuentemente demandadas por publicaciones con determinada línea editorial o cuando el medio tiene una intención informativa concreta.

En cualquier caso, es una tarea fundamental previa a la car- ga del material, ya que evitará documentar más imágenes de las necesarias, disminuirá la sobrecarga del sistema, y reducirá el ruido en las búsquedas. Este último es uno de los principales inconvenientes para el usuario, ya que un exceso de resultados obliga a la tediosa revisión de numerosas páginas con imágenes muy similares, en lugar de agilizar la localización de las deseadas.

\section{Diferencias descriptivas según el tipo de imágenes}

Una vez establecidas las principales características y dificultades de la descripción de imágenes para facilitar su localización y uso, a continuación se incluyen indicaciones y recomendaciones adaptadas a los distintos tipos de imágenes disponibles en las bases de datos que proporcionan este tipo de servicios.

La descripción de una imagen puede tener hasta tres niveles de profundidad, dependiendo del tipo de fotografía y del uso futuro que se pretenda lograr:

- Básico o esencial: breve descripción en texto libre del hecho principal que ilustra la imagen, situándolo en el espacio y en el tiempo. No se añadirán detalles ni aspectos secundarios ni se incluirá nada que no aparezca en la imagen. Esta información aparecerá como titular o caption y en la descripción de la imagen. La figura 4 reseña cargos que no aparecen en la imagen y obvia información necesaria como la distinción del cuerpo militar que desfila, en este caso soldados regulares.

- Enriquecido: dependiendo del tema se destacarán unos aspectos u otros al describir la imagen, enriqueciendo la 


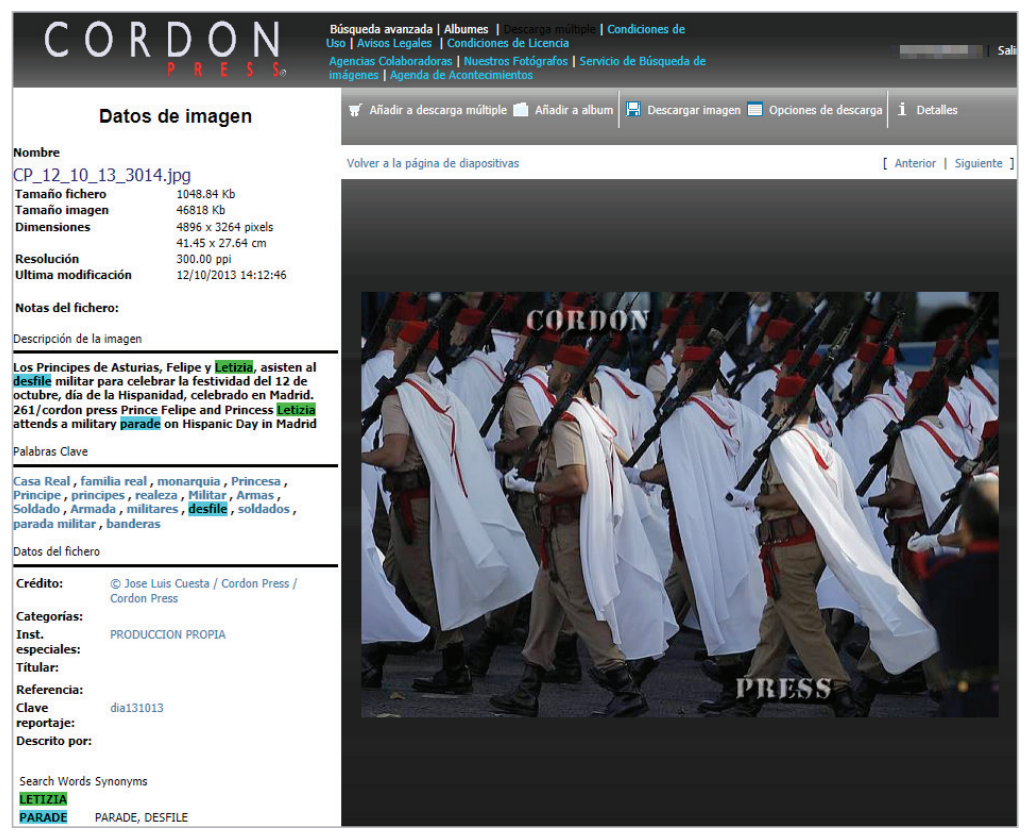

Figura 4. La descripción menciona personas que no aparecen en la imagen

descripción con palabras clave y dotándola de valor para usos futuros diferentes del original para el que fue tomada.

Creativo: este último nivel es el más complejo. Consiste en representar mediante palabras clave conceptos abstractos, creativos o emocionales de la imagen, más allá de lo físicamente evidente o lo explícito. Se trata de incluir las ideas, sentimientos y percepciones que provoca en la persona que observa la imagen o lo que trata de evocar quien la elige para un uso determinado. Es una labor totalmente subjetiva por lo que la elección de las palabras clave no siempre es trivial. Además, una misma imagen puede no sugerir lo mismo a todo el mundo. Por tanto, la descripción se centrará en lo más obvio y sencillo (a una foto de desplazados por la guerra de Siria se pueden añadir palabras clave como: pobreza, hambruna, infancia, tristeza; una foto histórica de una ciudad arrasada por bombardeos durante la Segunda guerra mundial puede incluir términos como destrucción o desolación), teniendo siempre presente que no todas las imágenes han de llegar necesariamente a este nivel de descripción.

Como parte de la documentación de fotografías también es necesario incluir cualquier condición especial que el usuario deba conocer y que diferencie a esa imagen de la mayoría de imágenes de agencia con condiciones generales:

- Restricciones de uso: por ejemplo limitaciones de uso en determinados países o tipos de publicaciones (prensa amarilla, de contenido sexual, etc.).

- Precios especiales: imágenes que por determinadas circunstancias no se incluyen en los acuerdos de precios generales establecidos entre clientes y bancos de imágenes (acontecimientos cubiertos en exclusiva).

- Gestión de derechos: bien de propiedad intelectual, por ejemplo en las imágenes de obras de arte (es obligación del que publica la imagen dirigirse a la Vegap para garantizar el cumplimiento de la ley, la agencia sólo debe mencionarlo adecuadamente en la descripción), o en los fotogramas de películas o de programas de televisión (requerirá la comunicación con las productoras o con la $S G A E$ ); bien derechos de imagen (personas, edificios o marcas comerciales).

\subsection{Descripción enriquecida}

Como se ha señalado ya, dependiendo del tema de la imagen es posible añadir mucha información mediante una adecuada elección de palabras clave para facilitar la reutilización de la fotografía en diferentes contextos. Se trata de prever los usos futuros de cada instantánea basándonos en las necesidades de nuestros usuarios, siempre incorporando detalles o aspectos que no han sido previamente incluidos en la descripción básica, y que las diferencien y destaquen del gran volumen de información gráfica disponible.

Partiendo de la descripción en texto libre y de lo que el documentalista observa en la fotografía, se añadirá todo aquello relevante no reseñado, tratando de adaptar esa descripción al tema y al tipo de imagen de que se trate. Estos dos aspectos son esenciales para la correcta descripción (Age Fotostock, 2014). Sin embargo, no existe un único criterio para determinar los temas y los tipos, siendo su establecimiento subjetivo y en muchos casos supeditado a los objetivos del banco de imágenes o a sus políticas documentales y editoriales. Es conveniente identificar una materia genérica inicial para cada imagen que permita una primera acotación de búsqueda, especialmente en el caso de agencias generalistas (actualidad, historia, deportes, espectáculos, viajes, etc.).

Una imagen puede no sugerir lo mismo a todo el mundo

Algunas de las categorías pueden superponerse, por lo que será competencia de la agencia determinar en su política documental/editorial la definición de esas categorías y qué tipos de imágenes incluirá cada una (establecer a partir de qué fecha se consideran fotografías históricas), así como los tipos más frecuentes de imágenes dentro de ellas (retratos, paisajes, escenas, bodegones), y el nivel de descripción deseable. De esta forma, tanto la política documental como el nivel de detalle en la descripción de las imágenes determinarán el tipo y la variedad de ayudas de búsqueda que la web ofrecerá a los usuarios (sinonimia, autocompletar, desambiguación).

De forma general para cualquier tema y tipo de imagen, pero sólo para aquellas que lo requieran, es posible indicar aspectos sobre la técnica fotográfica, los efectos especiales de luz (siluetas, contraluces), lentes poco comunes (ojo de pez, macro), perspectiva (cenital, picado, normal, contrapicado, nadir -hacia arriba-, vista aérea...), o al color dominante, entre otros. Los apartados siguientes detallan los principales aspectos a destacar según el tema de la fotografía. 


\subsection{Fotografía pe- riodística e informa- tiva}

Independientemente de su temática más concreta (política, historia, deportes, espectáculos), es imprescindible en este tipo de imágenes identificar correctamente las personas, lugares, acontecimientos y fechas que las contextualizan. Será indispensable la normalización de las nomenclaturas, es decir, confirmar la grafía correcta de nombres de personas, cargos que ocupan, la forma oficial o de uso más extendido para lugares, hechos históricos y acontecimientos políticos, deportivos, culturales o sociales para consignarlos de manera uniforme en sus distintas ediciones (gala de los Oscars, Festival de Cannes). Si hay varias acepciones posibles para un nombre, todas apuntarán a una única en el diccionario del motor de búsqueda para que sea cual fuere la forma usada por el usuario al realizar la búsqueda, el sistema incluya todas las variantes previamente identificadas. La opción de autocompletar por parte del sistema puede ayudar a minimizar este inconveniente y a facilitar la búsqueda.

Por lo que respecta a las fechas, se recogerán todas las nomenclaturas posibles para permitir búsquedas generales en el futuro, especialmente en fotografía histórica y artística (1925 apuntará a: siglo XX, 20’s, 20s, 1920s, 1920's, período de entreguerras o interbellum).

El mismo criterio se debe aplicar para la localización geográfica de la imagen, donde además de ser lo más concretos posibles a la hora de ubicarla en el espacio indicando país, ciudad, municipio y calle, habrá que añadir otros términos más generales y abstractos como región, barrio, continente, unión sociopolítica o comercial (Unión Europea, Mercosur), o destinos turísticos (Costa del Sol, Riviera Maya).

Por otro lado, si se trabaja con retratos de personas habrá que especificar la posición del sujeto frente a la cámara (frontal, perfil, desde atrás), si la persona está mirando a cámara o el tipo de plano (general o largo, americano/tres cuartos, medio, medio corto, primer plano, primerísimo primer plano, plano detalle). Esta información no es obligatoria en todos los retratos y se consignará sólo en aquellas imágenes que a juicio del especialista lo requieran. Asimismo, si las personas que aparecen en estas fotografías son conocidas, famosas, o importantes, además de su nombre se indicará su profesión (actriz, deportista -futbolista, tenista, piloto-, cantante, político, científico, diseñador, modelo), y su nacionalidad. Esto permitirá realizar búsquedas generales como diseñadores españoles o actores franceses evitando tediosas búsquedas por nombres.
Dentro de la fotografía informativa destaca la relevancia del mundo del espectáculo, que a su vez está íntimamente relacionado con el sector de la moda, por lo que resulta conveniente combinar esa información convergente (añadir el nombre del diseñador del vestido de una actriz en una gala o la marca de los complementos que lleva). En eventos sociales es frecuente que los fotógrafos realicen imágenes de detalle de los complementos, por lo que en este caso habrá que añadir la palabra clave "detalle" además del genérico para el tipo de complemento y la marca y/o diseñador (Bolso Choppard, detalle).

Otro sector destacado dentro de la fotografía informativa es el deportivo, por lo que también habrá que prestar una especial atención a la descripción de este tipo de instantáneas consignando, además de los aspectos anteriormente indicados, otros detalles o elementos distintivos (público, si es una imagen de las gradas; fans o seguidores, si aparecen caracterizados o portan banderas, pancartas o bufandas). También se han de indicar acciones de los deportistas que destaquen durante la acción general del juego no incluidas en el pie de foto (un gol, un golpeo de un tenista, un adelantamiento en una carrera), y aquellas que no tengan que ver directamente con el mismo (un futbolista bebiendo en la banda o un tenista secándose el sudor de la frente, que además ayudan en la adición de conceptos creativos no visuales como: esfuerzo o cansancio).

\subsection{Fotografía de viajes, naturaleza, fauna y flora}

En la fotografía de viajes el dato más importante a reseñar es la localización, que habrá de indicarse con el máximo grado de detalle posible (especificando hasta el nombre y el número de la calle). Al igual que en la fotografía informativa, habrá que normalizar las nomenclaturas de las localizaciones e incluir desde la ubicación más general (continente), a la más concreta (coordenadas GPS), además de recoger todas aquellas clasificaciones referidas al lugar fotografiado (socio-económicas, geopolíticas, comerciales o turísticas), que más tarde nos permitirán restringir las búsquedas.

También es importante establecer una primera aproximación al tipo de fotografía mediante descripciones como: 

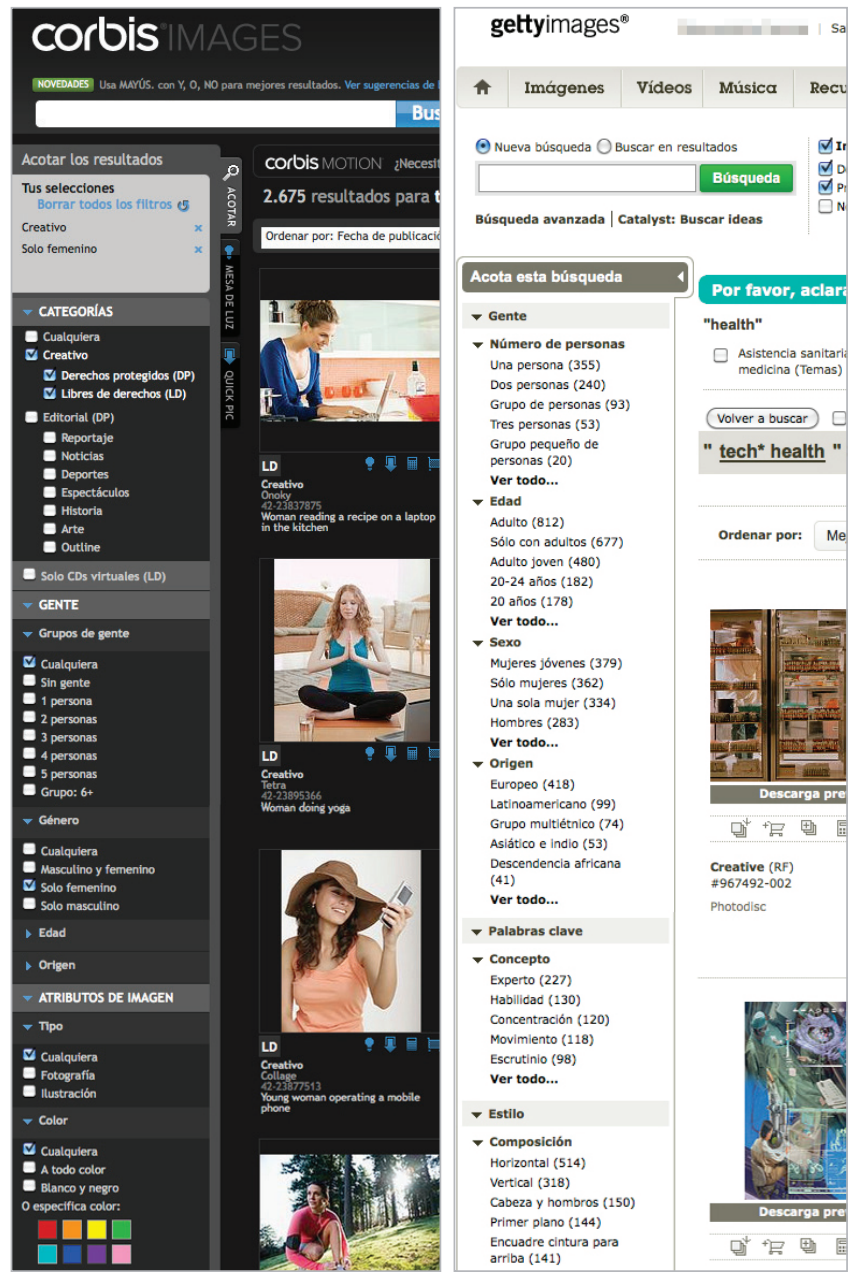

Figura 6. Búsqueda avanzada en Corbis y Getty. Incluye la opción de búsqueda "gente"

paisaje para vistas generales de lugares relacionados con la naturaleza, concretando con paisaje urbano para las vistas generales de ciudades o paisaje rural para las vistas generales de pueblos. En todos los casos es muy conveniente indicar "sin gente" o "nadie" como hecho diferenciador en los paisajes en los que no aparezcan personas. Por el contrario, la presencia de gente no ha de reseñarse salvo si fuera un hecho diferenciador llamativo (una o dos personas solas en una foto de un desierto, o una "multitud" en un determinado lugar). Para la descripción de lugares en los que aparecen personas se pueden utilizar los términos escena urbana o escena rural.

Por otro lado, es esencial indicar el momento del día en el que se ha tomado la foto si nos encontramos ante una fotografía nocturna, un amanecer o un atardecer, en contraposición a la mayoría de fotos realizadas de día. Aunque dispongamos de la fecha, en este tipo de imágenes habrá que destacar la estación del año cuando se trate de un hecho diferenciador (otoño en un paisaje con el suelo cubierto de hojas o con árboles con las hojas amarillas o rojas; invierno para un paisaje o ciudad nevados; primavera para un paisaje verde y con muchas flores; pero no verano para todas las fotos de playas soleadas).

En las fotografías de naturaleza de fauna y flora será imprescindible incluir el nombre científico y el nombre común de cada especie, y será conveniente especificar aspectos relativos al detalle de la imagen (si es un primer plano, un plano abierto, un plano parcial), mencionando en el caso de las imágenes de primer plano las partes significativas mostradas del animal o de la planta (cabeza, hocico, hoja, pétalo, pistilo). En el caso concreto de los animales, además, habrá que mencionar el sexo si se conoce, el número de animales presentes en la fotografía, si están desarrollando alguna actividad (cazando, alimentándose, corriendo, volando), la edad o términos relativos a la misma (potro, polluelo, cachorro), la especie (mamífero, herbívoro, depredador), o sus condiciones de vida (en cautividad, en peligro de extinción, especie protegida).

\subsection{Fotografía de stock}

Las fotografías de stock son imágenes tomadas para ilustrar conceptos, situaciones u objetos, donde la localización en el espacio y en el tiempo no es relevante. Para aquellas imágenes que incluyan personas será importante determinar el número de las que aparecen (nadie, una, dos, grupo, multitud).

Si se trata de primeros planos habrá que indicar la parte visible (cuerpo entero, cara, cabeza y hombros, mano, ojo), sexo, edad aproximada (mediante rangos definidos en la política documental), raza (asiático, afroamericano, hispano, caucásico), actividad que estén llevando a cabo (hablando, trabajando, riendo, comiendo), y si es relevante el lugar (hogar, oficina, restaurante), el rol que representan (madre, padre, médico, estudiante, jefe), las emociones que expresan (enfadado, felicidad, miedo, euforia), u otros detalles que destaquen como la ropa o la apariencia física.

En las imágenes de objetos (bodegones y naturalezas muertas) hay que incluir la cantidad y tipo de objetos fotografiados, las características importantes en cada caso (tamaño, color, aspecto, material), y los conceptos generales con los que estén relacionados (trabajo, deporte, artesanía). Es muy importante además destacar si es silueteable y si tiene un fondo plano, normalmente blanco o negro, dado que estas características facilitan la posterior manipulación de la imagen para integrarla en composiciones (Corbis, 2014).

\section{Conclusiones}

El volumen de fotografías digitales aumenta cada día de forma caótica y desordenada, careciendo en muchas ocasiones de una mínima descripción que permita su recuperación y utilización. Incluso las empresas dedicadas a su venta prestan una atención limitada a esta cuestión, priorizando otros objetivos como acuerdos preferentes que hagan aumentar el volumen del fondo disponible o el control de las descargas para su posterior facturación.

Sin embargo, de poco sirve una base de datos ingente, o un sistema perfecto a la hora de detectar las descargas en alta resolución si el usuario no puede acceder adecuadamente a ese fondo documental o si la fotografía tomada no puede rentabilizarse a través de segundos usos.

La descripción de imágenes no es una tarea trivial. A sus especiales características respecto a otros tipos documentales, se unen las diferencias que presentan en función de 
su tipo específico, requiriendo un tratamiento diferenciado y diversos aspectos no siempre coincidentes sobre los que hacer hincapié. Es a partir de este momento cuando el correcto y completo trabajo de descripción y documentación del especialista en información cobra especial relevancia para asegurar su recuperación y uso, situación que además repercutirá en la facilidad de manejo del sistema de búsqueda.

Por otra parte, los sistemas se muestran aún inmaduros en la localización automática de fotografías, a pesar de que los principales bancos de imágenes e incluso en algunos buscadores cuentan con herramientas destinadas a este propósito. La falta de precisión es mucho mayor cuando la búsqueda se basa en el reconocimiento de figuras, formas o colores (figura 7).

El reto del especialista es lograr que el sistema muestre las imágenes que se ajustan a las necesidades del cliente, no de inundar la pantalla con muchas imágenes que en ocasiones son muy parecidas o no tienen nada que ver con lo que se precisa. Es primordial realizar una descripción equilibrada, tanto en texto libre como a través de la asignación de palabras clave, evitando registros escuetos o incompletos, excesivamente recargados o demasiado imaginativos. En definitiva, ser capaces de plasmar el abanico de temas que la imagen podría ilustrar en el futuro de la forma más precisa y aséptica posible, poniendo de relieve el indisoluble vínculo que existe entre esa descripción y la satisfacción de la futura necesidad.

Es primordial realizar una descripción equilibrada, tanto en texto libre como en la asignación de palabras clave

Finalmente, la aplicación de las recomendaciones para la descripción diferenciada de fotografías mejorará la calidad de esas descripciones, facilitará el éxito en la recuperación, ayudará en la difícil tarea de normalización y aumentará las valoraciones positivas de las aplicaciones web por parte de clientes y usuarios.

\section{Notas}

1. Vegap = Visual Entidad de Gestión de Artistas Plásticos

2. SGAE = Sociedad General de Autores de España

\section{Bibliografía}

Age Fotostock (2014). "All about keywording". Nueva York: Age.

http://www.agefotostock.com/phroad/ingles/phroad06. asp

Boadas, Joan; Casellas, Lluís-Esteve; Suquet, M. Àngels
(2001). "Manual para la gestión de fondos y colecciones fotográficas". Girona: CCG Editores.

http://www.girona.cat/sgdap/docs/0256_Manual_ Fotografic.pdf

Charbonneau, Normand; Robert, Mario (1999). "La description des photographies". Archives (Québec), v. 30, n. 1, pp. 25-43.

Codina, Lluís (2011). "Entender los bancos de imágenes". El profesional de la información, v. 20, n. 4, pp. 417-423.

http://eprints.rclis.org/16036/1/bancos/magenes_2011.pdf http://dx.doi.org/10.3145/epi.2011.jul.08

Corbis (2014). Encontrar el formato correcto de la imagen. Seattle: Corbis.

http://www.corbisimages.com/content/searchtips/\#/ search/encontrar-el-formato-correcto-de-la-imagen

Del-Valle-Gastaminza, Félix (1999). "El análisis documental de la fotografía”. En: Manual de documentación fotográfica. Madrid: Síntesis, pp. 113-132. ISBN : 8477386897

Del-Valle-Gastaminza, Félix (2001). “El análisis documental de la fotografía". Madrid: Universidad Complutense. http://pendientedemigracion.ucm.es/info/multidoc/prof/ fvalle/artfot.htm

Doucet, Anne-Vinciane (2008). "La descripción de las imágenes en internet a través del análisis de 30 bancos de imágenes". Revista general de información y documentación, v. 18, pp. 81-105.

http://revistas.ucm.es/index.php/RGID/article/view/ RGID0808110081A

Getty Images (2014). Información sobre la licencia de uso. Seattle: Getty.

http://www.gettyimages.es/Corporate/Licenselnfo.aspx

Hollink, Laura; Schreiber, Guus; Wielinga, Bob; Worring, 
Marcel (2004). "Classification of user image descriptions". Intl journal of human-computer studies, v. 61, n. 5, pp. 601626.

http://www.cs.vu.nl/ /aurah/papers/Hollink_coid.pdf http://dx.doi.org/10.1016/j.ijhcs.2004.03.002

Iglesias-Franch, David (2008). La fotografía digital en los archivos. Gijón: Trea.

Lee, Hyuk-Jin; Neal, Diane (2010). "A new model for semantic photograph description combining basic levels and userassigned descriptors". Journal of information science, v. 36, n. 5, pp. 547-565.

http://ir.lib.uwo.ca/cgi/viewcontent.cgi?article=1018\&cont ext=fimspub

http://dx.doi.org/10.1177/0165551510374930

Lin, Chia-Hung; Yen, Chia-Wei; Hong, Jen-Shin; Cruz-Lara, Samuel (2008). "Event-based knowledge extraction from free-text descriptions for art images by using semantic role labeling approaches". The electronic library, v. 26, n. 2, pp. 215-225.

http://dx.doi.org/10.1108/02640470810864109

Ménard, Elaine; Smithglass, Margaret (2012). “Digital image description: a review of best practices in cultural institutions". Library hi tech, v. 30, n. 2, pp. 291-309.

http://dx.doi.org/10.1108/07378831211239960

Muñoz-Castaño, Jesús E. (2001). “Bancos de imágenes: evaluación y análisis de los mecanismos de recuperación de imágenes". El profesional de la información, v. 10, n. 3, pp. 4-18.

http://eprints.rclis.org/11751/1/Bancos_de_im\%C3\%A1genes. $p d f$

Perdices-Castillo, Luisa; Perianes-Rodríguez, Antonio (2011). "Sistemas de búsqueda y visualización en bancos de imágenes comerciales". El profesional de la información, v. 20, n. 4, pp. 439-443.

http://eprints.rclis.org/16600/1/Perdices_EPI_2011.pdf http://dx.doi.org/10.3145/epi.2011.jul.11

Robledano-Arillo, Jesús (2002). "El tratamiento documental de la fotografía de prensa: sistemas de análisis y recuperación". Madrid: Archiviana. ISBN: 9788495933027

Robledano-Arillo, Jesús (2007). "Estándares para la descripción de fotografía”. Revista d'arxius, v. 6, pp. 149-188.

Robledano-Arillo, Jesús; Moreiro-González, José-Antonio (2002). "La recuperación documental de la imagen fotográfica: perspectiva tecnológica y documental”. En: Primeras Jornadas Imagen, Cultura y Tecnología. Madrid: Archiviana, pp. 179-200. ISBN: 8495933063

http://e-archivo.uc3m.es/handle/10016/8951

Rorissa, Abebe (2008). "User-generated descriptions of individual images versus labels of groups of images: a comparison using basic level theory". Information processing \& management, v. 44, n. 5, pp. 1741-1753.

http://dx.doi.org/10.1016/j.ipm.2008.03.004

El profesional de la información The information professional INTERNATIONAL JOURNAL ON INFORMATION AND COMMUNICATION

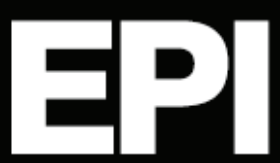

\section{EPI deja la edición en papel}

Adaptándose a los nuevos tiempos, a partir del próximo mes de enero de 2015 esta revista El profesional de la información va a publicarse sólo online.

Al mismo tiempo, debido al cese de actividad en abril de 2015 de la empresa MetaPress, del grupo Ebsco, la revista se instalará en el Repositorio Español de Ciencia y Tecnología (Recyt) de la Fundación Española para la Ciencia y la Tecnología (Fecyt): http://recyt.fecyt.es/index.php/EPI

Desde ahí los suscriptores podrán acceder a los contenidos desde el año 2000 hasta la actualidad.

La web http://elprofesionaldelainformacion.com continuará funcionando como ahora, con toda la información sobre la revista, y los contenidos 1992-2010. 